\title{
IMPLEMENTASI PEMBELAJARAN YOGA DALAM MENINGKATKAN KONSENTRASI BELAJAR DI SEKOLAH DASAR NEGERI 1 SUMERTA
}

\author{
Oleh \\ I Ketut Gunarta \\ Institut Hindu Dharma Negeri Denpasar \\ toetgoen@gmail.com
}

Diterima 03 Juli 2017, direvisi 07 Agustus 2017, diterbitkan 31 Agustus 2017

\begin{abstract}
The influence of modernization needs to be balanced with physical and spiritual health so that people can work, human beings can accept, recognize and direct themselves. Healthy living is the dream and goal of every person. No one in this world expects his life to be sick, because in a state of sickness a human body will find it difficult to achieve his purpose in life. Among teenagers often occur deviant behaviors that interfere with health itself is also disrupt in the activity in school and environment.

The moral degradation experienced by the younger generation is very important to be given guidance from parents, educators, community and government. Yoga practice implies the sradha strengthening and devotion to God, which can form the character of a virtuous, emotionally and spiritually intelligent young generation who is able to counteract the negative effects of globalization, provide peace of mind, body health and foster a sense of compassion for others, which can reduce stress. Yoga is included in the universal doctrine therefore everyone should be able to control all of his actions, protect, regulate and discipline his mind so as not to deviate from the teachings of dharma.
\end{abstract}

Keywords: Implementation, Instruction, and Yoga.

\section{PENDAHULUAN}

Perkembangan ilmu pengetahuan dan teknologi memberikan begitu banyak kemudahan dalam kehidupan namun tidak setiap kemudahan memberikan dampak positif. Justru dengan berbagai kemudahan telah menjadikan manusia semakin jauh dari arti dan makna kehidupan yang sesungguhnya. Sebagaimana yang dinyatakan Radhakrisnan (1987: 9) bahwa kemanusiaan sekarang ini mengalami krisis terbesar sepanjang sejarah umat manusia. Perkembangan sains dan 
teknologi tidak disertai dengan kemajuan yang sama dibidang spiritualitas, bahkan spiritualitas makin rapuh dibawa arus materialisme, hedonisme, pragmatisme peradaban modern. Perkembangan ilmu pengetahuan dan teknologi membuat manusia semakin pintar memparasitkan diri kepada alam dan mengejar hidup yang sifatnya kebendaan saja.

Setiap orang nampak sulit dalam menguasai dan mengendalikan dirinya, tercermin melalui perilaku suka menganiaya, membakar, bahkan membunuh. Peradaban kemanusiaan seolah-olah bergeser demikian jauh, hati manusia seolah telah menjadi batu, begitu keras, sehingga sulit sekali diencerkan dengan perkataan maaf. Menurut Donder (2004:117) mengatakan bahwa kehidupan dewasa ini semakin kompleks dan kompetitif, kebanyakan orang menjadi tidak tabah dan cepat putus asa, selanjutnya mengambil jalan pintas. Dapat diartikan pada dasarnya manusia menginginkan kebahagiaan, kedamaian, keamanan, dan ketentraman, serta berbagai hal yang baik. Namun melihat kondisi sekarang, ketentraman hidup, sopan santun, etika dan budi pekerti terabaikan.

Pada kalangan remaja sering terjadi perilaku-perilaku menyimpang yang dengan sendirinya mengganggu kesehatan dirinya sendiri juga mengganggu dalam beraktivitas di sekolah dan lingkungannya. Seperti sikap dan etika siswa terhadap gurunya di sekolah sangat kurang, sering terjadi perselisihan yang berujung pada tawuran, pemakaian obat-obatan terlarang (narkoba), dan terjadinya hubungan seks bebas. Sedangkan dalam kehidupan bermasyarakat sering terjadi perilaku-perilaku yang sepatutnya tidak menjadi contoh, seperti kurangnya sikap saling menghargai, kurangnya toleransi antar sesama, menurunnya nilai gotong royong, sering terjadi pertengkaran antar warga masyarakat, rendahnya disiplin kerja, pengangguran, perjudian, perceraian, pemerkosaan, pelacuran, penculikan, terjadinya krisis nilai-nilai etika moralitas dalam keluarga seperti anak yang berani melawan dan menentang orang tuanya, bersikap apriory terhadap keluarga merupakan gejala rendahnya pengembangan nilai-nilai susila dan etika tersebut.

Fenomena di atas memerlukan upaya dalam rangka memperbaiki kondisi sikap dan perilaku generasi muda. Tingkat kenakalan remaja menunjukan gejala kurang berkembangnya dimensi sosial dan kesusilaan mereka. Demikian juga kurangnya penghayatan terhadap nilai-nilai Ketuhanan dan praktekpraktek kehidupan yang tidak didasarkan atas ajaran agama yang menggambarkan kurang mantapnya pengembangan dimensi keragamaan. Generasi muda sebagai tulang punggung bangsa dan penerus masa depan yang perlu diarahkan untuk merubah kondisi dimulai dari dalam diri sendiri, merubah sikap dan perilaku untuk membentuk sikap keberagaman.

Pembelajaran dan penanaman nilai-nilai budi pekerti, etika dan moral untuk membentuk sikap generasi muda, salah satunya dengan memberikan pengetahuan dan pelatihan Yoga untuk mengembangkan kepribadian yang lebih kuat, sehingga memiliki sraddha dan bhakti yang mantap, bertanggung jawab serta terbentuknya sikap keberagamaan pada diri remaja. Untuk mewujudkan hal tersebut dukungan dari keluarga sangatlah penting, di samping memperdalam dengan pendidikan agama dan pengembangan diri yang sudah diperoleh. Dengan pembelajaran Yoga dapat meningkatkan kesehatan secara menyeluruh jasmani maupun rohani, sehingga mengurangi krisis etika moral dan terbentuknya sikap keberagamaan. Upaya-upaya yang harus dilakukan untuk mencegah pergeseran sikap dan perilaku generasi muda tersebut, terutama sikap saling menghormati antar sesama antara lain dengan mempertebal penghayatan ajaran agama dan pengembangan diri melalui kegiatan-kegiatan penanaman nilai-nilai budi pekerti, serta dengan mengikuti pembelajaran dan pelatihan Yoga secara intensif. 
Yogamerupakan salah satu metode untuk mencapai keselarasan tubuh, pikiran, dan jiwa serta untuk mencapai penerangan rohani. Metode-metode ini diajarkan sesuai dengan tingkat perkembangan rohani seseorang. Selain itu, Yoga memiliki fungsi sebagai berikut: 1) Untuk mengendalikan pikiran yang terobjektifkan dan kecenderungan alami pikiran, 2) Untuk mengatur semua pemikiranpemikiran dan kegelisahan-kegelisahan dan tetap tak terpengaruh, dan 3) Penyatuan antara kesadaran unit dan kesadaran kosmik (Kamajaya, 1993: 20).

Pembelajaran Yoga pada anak di sekolah dasar menitikberatkan pada penyatuan pikiran, tubuh dan jiwa, serta membangkitkan koneksi antara anak dan lingkungannya. Pembelajaran Yoga pada intinya bertujuan untuk membantu anak peserta didik untuk merasakan kebahagiaan, kebebasan dan pencerahan. Anak-anak jaman sekarang, selalu disibukan dengan aktivitas yang cukup padat. Mulai dari kegiatan sekolah, ekstrakurikuler, les hingga PR dari sekolah. Kegiatan-kegiatan tersebut dapat membuat mereka stres, kurang konsentrasi dan merasa kelelahan. Berikan keseimbangan dalam hidup anak-anak dengan mengikutkan mereka latihan Yoga, karena Yoga bermanfaat untuk fisik, mental dan spritual.

\section{PEMBAHASAN}

\subsection{Implementasi}

Istilah implementasi, dalam Kamus Besar Bahasa Indonesia (Depdiknas, 1994 : 379) berarti pelaksanaan, penerapan. Secara sederhana implementasi bisa diartikan pelaksanaan atau penerapan. Browne dan Wildavsky (dalam Nurdin dan Usman, 2004: 70) mengemukakan bahwa "implementasi adalah perluasan aktivitas yang saling menyesuaikan". Pengertian implementasi bermuara pada aktivitas, adanya aksi, tindakan, atau mekanisme suatu sistem. Ungkapan mekanisme mengandung arti bahwa implementasi bukan sekadar aktivitas, tetapi suatu kegiatan yang terencana dan dilakukan secara sungguh-sungguh berdasarkan acuan norma tertentu untuk mencapai tujuan kegiatan. Oleh karena itu, implementasi tidak berdiri sendiri tetapi dipengaruhi oleh obyek berikutnya yaitu kurikulum. Dalam konteks implementasi, pendekatan-pendekatan yang telah dikemukakan di atas memberikan tekanan pada proses. Esensinya implementasi adalah suatu proses, suatu aktivitas yang digunakan untuk mentransfer ide/gagasan, program atau harapan-harapan yang dituangkan dalam bentuk kurikulum desain (tertulis) agar dilaksanakan sesuai dengan desain tersebut. Masing-masing pendekatan itu mencerminkan tingkat pelaksanaan yang berbeda.

Kaitannya dengan pendekatan yang dimaksud, bahwa pendekatan pertama, menggambarkan implementasi itu dilakukan sebelum penyebaran (desiminasi). Kata proses dalam pendekatan ini adalah aktivitas yang berkaitan dengan penjelasan tujuan program, mendeskripsikan sumber-sumber baru dan mendemosntrasikan metode pengajaran yang diugunakan. Pendekatan kedua, menekankan pada fase penyempurnaan. Kata proses dalam pendekatan ini lebih menekankan pada interaksi antara pengembang dan guru (praktisi pendidikan). Pengembang melakukan pemeriksaan pada program baru yang direncanakan, sumber-sumber baru, dan memasukan isi/materi baru ke program yang sudah ada berdasarkan hasil uji coba di lapangan dan pengalaman-pengalaman guru. Interaksi antara pengembang dan guru terjadi dalam rangka penyempurnaan program, pengembang mengadakan lokakarya atau diskusi-diskusi dengan guru-guru untuk memperoleh masukan. Implementasi dianggap selesai manakala proses penyempurnaan program baru dipandang sudah lengkap. Sedangkan pendekatan ketiga, implementasi sebagai bagian dari program kurikulum. Proses 
implementasi dilakukan dengan mengikuti perkembangan dan megadopsi programprogram yang sudah direncanakan dan sudah diorganisasikan dalam bentuk kurikulum desain (dokumentasi). Penelitian ini dimaksudkan proses implementasi pembelajaran yogapada peserta didik SDN 1 Sumerta.

\subsection{Yoga}

Kata Yogaberasal dari akar kata "yuj" yang artinya menghubungkan dan yogaitu sendiri merupakan pengendalian aktivitas pikiran dan merupaka penyatuan roh pribadi dengan roh tertinggi. Pendiri dari sistem Yogaadalah HiraGyagarbha dan yogayang didirikan oleh Mahârci Pataòjali merupakan cabang atau tambahan dari filsafat SâAkhya, yang memiliki daya tarik tersendiri bagi para murid yang memiliki temperamen mistis dan perenungan, dikatakan bahwa yoga bersifat lebih orthodox dari pada filsafat SâAkhya, karena yogasecara langsung mengakui keberadaan Îsvara, sehingga sistem filsafat dari Pataòjali ini merupakan Sa-îsvara (Maswinara, 1999: 163). Hal ini senada dengan Somvir (2008), menyatakan bahwa Yogaberasal dari kata yuj yang artinya menyatukan diri dengan Tuhan. Selain itu Yogaadalah penyatuan, yakni penyatuan antara jiwa spiritual individu dengan jiwa universal, Yogajuga disebut pembatasan pikiran yang selalu bergerak. Dengan latihan Yoga juga dapat memperlancar darah, distribusi udara yang dibutuhkan oleh tubuh, dan dapat mencegah bahkan menyembuhkan beberapa jenis penyakit.

Madja (2008), lebih menekankan pada perbandingan antara konsep yoga patanjali dengan konsep Yoga Wrhaspati Tattwa. Dalam konsep yoga patanjali dan yoga wrhaspati tattwa memiliki tahapan-tahapan yoga masing-masing, dan juga terdapat fungsi serta makna dari tahapan-tahapannya itu sendiri. Tahapan-tahapan yoga dalam konsep yoga sutra patanjali meliputi Astangga Yoga yang terdiri dari yama, niyama, asana, pranayama, pratyahara, dharana, dhyana, dan Samadhi. Sedangkan tahapan-tahapan Sadangga Yoga dalam konsep YogaWrhaspati Tattwa terdiri dari: pratyahara, dhyana, pranayama, dharma, tarka, dan Samadhi.

Somvir (2008) mengatakan bahwa yogaadalah penyatuan antara jiwa spiritual individu dengan jiwa universal, yang disebut juga pembatasan pikiran yang selalu bergerak. Dalam hal ini Vivekananda (2008: 187) menyatakan bahwa dalam latihan Yoga harus memenuhi tiga syarat, yaitu: 1) melepaskan semua kesenangan duniawi, 2) memiliki keinginan kuat dan kebenaran, dan 3) menjaga pikiran yang berkelana, menjaga indera, mengalihkan pikiran ke dalam, menderita tanpa mengeluh, menguatkan pikiran akan ide tertentu dan berfikir selalu tentang sifat. Sedangkan dalam kamus Bahasa Indonesia disebutkan bahwa pengertian Yogaadalah semadi, tafakur, menghentikan pikiran dan berusaha menguasai diri, adalah semadi, tafakur, menghentikan pikiran dan berusaha menguasai diri, Yogajuga berarti senam (gerak badan) dan latihan pernafasan untuk menjaga kesehatan tubuh dan jiwa (Zain, 2001: 1633).

Yogamerupakan satu pelajaran harmonisasi untuk manusia agar ia mampu hidup bahagia, damai, dan berharga untuk mengembangkan nilai-nilai kemanusiaannya yang tertinggi, supaya mampu meningkatkan derajat hidup yang terbaik, agar sifat ilahi dalam manusia berwujud nyata pada dirinya serta mencapai pembebasan hidup, Yogajuga dapat meningkatkan kesehatan serta menciptakan keselarasan antara tubuh, pikiran dan jiwa sehingga terbentuk kepribadian yang luhur dan dapat mengembangkan keberagaman pada diri masing-masing siswa Yoga (Suhardana, 2006: 18).

Manfaat yang terpenting disebutkan adalah dapat menjaga kondisi fisik maupun pikiran senantiasa dalam keadaan sehat dan bahagia serta meningkatkan daya tahan tubuh 
menghadapi perubahan cuaca. Dalam memahami Yoga yang diperkenalkan oleh Maha Rsi Patanjali, yaitu Astangga Yoga, seseorang akan menjadi sehat secara fisik, mental, moral, dan spiritual. Yoga tidak cukup hanya sekedar latihan asanas saja, melainkan harus bisa dicerminkan dari sikap, perilaku yang baik dalam kehidupan sehari-hari, karena Yoga memberikan kesehatan secara menyeluruh baik secara fisik maupun rohani. Patanjali menjelaskan empat prinsip yang harus diikuti oleh praktisi Yoga dalam kehidupan sehari-hari. Pada awalnya hal ini memang terasa sulit dilakukan secara menyeluruh, namun oleh praktisi Yogadan dengan tuntunan seorang guru, siswa dapat melaksanakan dan mempraktekannya setiap hari.

\subsection{Implementasi Pembelajaran Yoga}

\section{a. Menyehatkan Fisik}

Gerakan surya namaskara memberikan sejumlah manfaat umum dan memiliki pengaruh yang sangat kuat pada semua jaringan tubuh seperti kelenjar endokrin, peredaran darah, pernafasan, pencernaan, dan juga untuk peningkatan konsentrasi. Dibawah ini dijelaskan kedua belas gerakan yang dimaksud.

1) PraGamâsana (Sikap Berdoa) adalah sikap berdiri tegak dengan kedua kaki dibuka satu kali lebar bahu. Kedua telapak tangan diletakkan secara bersamaan di depan dada. Kendorkan seluruh tubuh. Pandang lurus ke depan.Nafas:Secara perlahan nafas dihembuskan. Manfaatnya: Membentuk suatu keadaan konsentrasi dan ketenangan dalam persiapan untuk melakukan latihan dan menghadapi alam semesta (Saraswati, 2002: 16).

2) Hasta Uttanâsana (Sikap Kedua Lengan Terangkat) dilakukan dengan mengangkat kedua lengan diatas kepala. Kedua lengan direnggangkan menurut lebar bahu masing-masing, kedua telapak tangan bisa disatukan atau dihadapkan keatas. Tekuk kepala dan tubuh bagian atas ke belakang, pandang sejauh mungkin ke belakang. Pinggul sedikit diangkat keatas. Nafas:tarik nafas ketika mengangkat tangan keatas. Manfaat: merenggangkan isi rongga perut, menghilangkan kelebihan lemak, dan memperbaiki pencernaan. Melatih otot-otot lengan dan bahu, menyelaraskan urat-urat syaraf, tulang belakang, dan membuka seluruh bilik paru-paru (Saraswati, 2002: 17).

3) Pâdahastâsana (Sikap tangan sampai kaki) dilakukan dengan cara membungkuk ke depan sampai jarijari tangan atau kedua tangan menyentuh tanah pada tiap sisi atau di depan kedua kaki. Coba untuk mencium lutut. Kedua lutut tetap lurus tanpa ditekuk, dan konsentrasikan pandangan pada lutut.Nafas: Hembuskan nafas selama membungkuk kedepan. Manfaat: Dapat melenyapkan atau mencegah sakit perut dan juga berbagai penyakit perut lainnya. Mengurangi kelebihan lemak pada daerah perut, memperbaiki pencernaan, melancarkan peredaran darah. Membuat tulang belakang menjadi lemas (Saraswati, 2002: 18).

4) Aava Sancalanâsana (Sikap menunggang kuda)

Letakkan kedua tangan pada kedua sisi kaki, tekuk lutut kaki kanan sambil melempar kaki yang sebelah kiri sejauh mungkin ke belakang. Jempol dan lutut kaki kiri menyentuh lantai, jari kaki kiri ditekuk. Panggul dicondongkan ke depan, lengkungkan tulang belakang dan menengadah. Tubuh dalam keadaan seimbang.Nafas:Tarik nafas ketika merentangkan kaki kiri ke 
belakang dan mendongak keatas. Manfaat:Memijat organ-organ perut dan memperbaiki fungsinya. Otot-otot kaki akan diperkuat. Keseimbangan urat syaraf akan tercapai (Saraswati, 2002: 19).

5) Parvatâsana (Sikap gunung) di mana kaki kanan diletakkan dibelakang dan berdampingan dengan kaki kiri. Perlahan angkat pantat keatas sedikit demi sedikit dan rendahkan posisi kepala dan letakkan diantara kedua lengan, sehingga tubuh membentuk segitiga dengan lantai. Letakkan tumit pada lantai pandangan diarahkan ke lutut lehernya dilipat kedalam. Nafas dihembuskan selama meluruskan kaki dan membungkukan tubuh.Manfaat: menguatkan syaraf dan otot-otot pada kedua lengan dan kaki. Melenturkan tulang belakang, pada arah yang berlawanan menuju sikap sebelumnya dan lebih jauh membantu membuatnya lemas. Menyelaraskan urat syaraf tulang belakang dan melancarka peredaran serta meningkatkan konsentrasi (Saraswati, 2005: 20).

6) Astângga Namaskâra (Pemberi hormat dengan 8 anggota badan) Tekuk lutut kelantai, letakkan dada dan dagu kelantai, pertahankan agar pantat tetap berada diatas. Kedua tangan, dagu, dada, lutut dan jari kaki menyentuh lantai serta tulang belakang dilengkungkan.Nafas tetap dalam penghembusan seperti parvatâsana hanya pada tahap ini penarikan nafas dan penghembusan nafas berubah bergantian. Manfaat: menguatkan otot kaki dan lengan serta memperkuat otot dada beserta perut (Saraswati, 2005: 21).

7) BhujaEgâsana (Sikap ular kobra) posisi rendahkan pinggul sementara mendorong dada kedepan dan keatas dengan bertumpu pada lengan, sampai tulang belakang melengkung kedua kaki dibelakang jangan dilipat atau diluruskan kedepan dan kepala didongakkan keatas. Kaki dan perut bagian bawah tetap berada dilantai dan lengan menyokong tubuh.Nafas: tarik nafas ketika mendongakkan kepala keatas dan membuka rongga dada ketika melengkungkan tulang belakang.Manfaat:perut ditekan, membantu menekan darah yang berhenti dari organ-organ perut dan mendorong aliran darah segar. Sikap ini sangat bermanfaat bagi semua penyakit perut, termasuk ketidak mampuan mencerna dan sembelit. Melengkungkan punggung melatih tulang belakang, membuat otot-otot lemas dan meningkatkan konsentrasi (Saraswati, 2005: 22).

8) Parvatâsana (Sikap gunung) posisi ini mengulang posisi 5. Pertahankan agar lengan dan lutut lurus. Sementara menggunakan bahu sebagai titik putar, angkat pantat dan turunkan kepala lipat lehernya, pandangan kelutut (Saraswati, 2002: 23).

9) Aava Sancalanâsana (Sikap menunggang kuda) posisi ini mengulang posisi 4. Tarik kaki kanan kedepan, dan letakkan kaki kanannya tepat ditengah-tengah kedua tangan. Secara perlahan letakkan lutut kiri kelantai dan dorong panggul kedepan. Lengkungkan tulang belakang dan pandang sejauh mungkin ke belakang (Saraswati, 2005: 24).

10) Pâdahastâsana (Sikap tangan sampai kaki)posisi ini mengulang posisi 3. Letakkan kaki kiri sejajar dengan kaki kanan dan luruskan, tekuk kedepan dan naikan pantat saat kepala diletakkan pada lutut. Kedua 
tangan tetap diletakkan disamping kaki (Saraswati, 2002: 25).

11) Hasta Uttanâsana (Sikap kedua lengan terangkat)posisi ini mengulang posisi 2. Angkat atau jantaikan tangan diatas kepala. Kedua tangan bisa disatukan atau telapak tangannya dihadapkan keatas. Lengkungkan punggung dan angkat sedikit pinggulnya (Saraswati, 2002: 26).

12) PraGamâsana (Sikap berdoa) posisi ini mengulang posisi 1. Turunkan kedua tanggan dan cakupkan kedua tangan di depan dada (Saraswati, 2002: 27).

Setelah melakukan pelatihan ekstrakurikuler Yoga âsana, diungkapkan bahwa setiap selesai mendapatkan ekstrakurikuler Yoga âsana fisik menjadi lebih bugar, tidak malas seperti di hari-hari yang lainnya dan ketika menerima pelajaran lebih semangat serta tidak ngantuk dan lebih fokus terhadap pelajaran yang diberikan di kelas.Manfaat fisik dalam melaksanakan yoga yaitu: a) Fleksibilitas merupakan gerakan-gerakan Yoga dapat membantu meregangkan dan meningkatkan fleksibilitas tubuh. Seiring waktu, seseorang dapat meningkatkan kelenturan paha belakang, punggung, bahu, dan pinggul dengan melakukan Yoga secara teratur; b) Kekuatan, didapatkan dari berbagai pose Yoga yang mengharuskan seseorang untuk mendukung berat tubuh sendiri, termasuk menyeimbangkan tubuh pada satu kaki atau mendukung tubuh dengan tangan. Beberapa latihan mengharuskan seseorang untuk berpindah dari satu pose ke pose yang lain yang juga akan meningkatkan kekuatan; c) Mengembangkan otot, selain melatih kekuatan tubuh, Yoga juga dapat meningkatkan massa otot. Sehingga otot-otot tubuh akan semakin kencang; d) Mencegah nyeri, meningkatnya fleksibilitas dan kekuatan tubuh dapat membantu mencegah sakit punggung. Banyak orang yang menderita sakit punggung karena menghabiskan banyak waktu duduk di depan komputer atau mengemudi mobil. Yoga dapat melemaskan kembali tulang dan otot yang kaku sehingga mencegah nyeri punggung; d) Memperlancar pernapasan, latihan pernapasan Yoga, yang disebut Pranayama yaitu memberi perhatian pada nafas dan mengajarkan bagaimana kita dapat menggunakan paru-paru untuk meningkatkan taraf kesehatan. Latihan napas juga dapat membantu membersihkan saluran hidung dan bahkan menenangkan sistem saraf pusat.

\section{b. Menyeimbangkkan Emosi}

Pelatihan ekstrakurikuler Yoga âsana yang dilakukan di SDN 1 Sumerta dari tahun 2014 banyak sekali memberikan perubahan bagi perilaku anak-anak (siswa) seperti mampu mengendalikan diri, emosi, lebih rajin belajar dan juga dapat mebentuk karakter anak menjadi lebih baik serta anak-anak dianggap lebih mampu untuk menerima pelajaran yang diberikan oleh guru di kelas. Implementasi ajaran Yoga baik saat di kelas ataupun di luar kelasyang sudah diterapkan di SDN 1 Sumerta memberikan dampak yang baik untuk meningkatkan konsentrasi belajar siswa sehingga prestasi yang diperoleh SDN 1 Sumerta menjadi meningkat.

Manfaat Mental latihan Yoga dapat memberi pengaruh positif yaitu a) Ketenangan pikiran dan mental, Yoga juga memiliki teknik meditasi yang bermanfaat untuk membantu menenangkan pikiran; b) Mengurangi stres, Yoga memiliki manfaat mengurangi stres. Saat berkonsentrasi, masalah sehari-hari baik besar maupun kecil akan mencair sehingga seseorang akan terbebas dari tekanan stres. Konsentrasi bisa menjadi sarana relaksasi pikiran yang sangat dibutuhkan oleh pikiran yang sedang stress; c) Kesiagaan tubuh, dengan melakukan Yogaakan memberikan peningkatan kesadaran dan kesiagaan tubuh. Karena banyak gerakan halus Yoga yang dapat meningkatkan keselarasan. 
Sehingga Yoga memiliki banyak manfaat bagi ketenangan pikiran, kesehatan, kesimbangan dalam pengontrolan emosi, mengatasi masalah dengan keadaan emosi yang positif, dan berbagaimacam solusi dapat ditemukan untuk mengatasi permasalahan kehidupan dengan cara tekun melaksanakan Yoga.Kecerdasan/kemampuan mengontrol emosi adalah bekal terpenting dalam mempersiapkan anak menyongsong masa depan, karena dengannya seseorang akan dapat berhasil dalam menghadapi segala macam tantangan, termasuk tantangan untuk berhasil secara akademis maupun non akademis.

\section{c. Meningkatkan Konsentrasi}

Dalam meningkatkan konsentrasi dilakukan dengan sikap berdiri (pada âsana) di mana dalam sikap berdiri tersebut siswa sudah diajarkan âsana dalam Yoga. Posisi berdiri yang diajarkanpun tidak hanya sekedar berdiri, di mana kedua kaki harus lurus, punggung leher kepala juga harus lurus dan pandangan ke depan. Dengan hal sederhana itu saja siswa sudah diajarkan untuk memfokuskan pikiran pada satu titik, yang dapat melatih konsentrasi mental siswa tersebut.

Menurut Tim Penyusun (2006: 71-72) yoga mengajarkan bermacam-macam âsana untuk memilihara kesehatan badan dan penyucian pikiran. Dengan âsana seseorang akan mampu mengerjakan kerja sistem syaraf agar terhindar dari goncangan-goncangan pikiran .

Tulang belakang memainkan peranan penting dalam menyeimbangkan tubuh. Ketika tubuh sudah seimbang maka pikiran juga akan seimbang sehingga konsentrasi akan terjaga. Ilmu fisika mengajarkan bahwa untuk memperoleh keseimbangan tubuh, maka sumbu dari gaya tarik harus jatuh diantara kedua belah kaki apabila mereka direntangkan. Tetapi jika seseorang membungkukkan tulang belakangnya ke depan maka ia memindahkan titik berat badannya ke depan dan titik berat tersebut tidak lagi terletak diujung kaki, sehingga keseimbangan tubuh jadi terganggu sehingga konsentrasi akan terganggu pula (Acarya, 2013: 23).

Ajaran-ajaran Yogasederhana yang dilakukan oleh siswa di kelas dari mulai proses belajar mengajar sampai selesai proses belajar mengajar siswa bisa lebih fokus dalam menerima pelajaran, dan konsentrasi siswa juga lebih meningkat, walaupun belum semua siswa bisa melakukan kegiatan tersebut dengan baik tetapi sudah ada banyak perubahan yang terjadi semenjak adanya penerapan ajaran Yogabaik saatdi kelas ataupun saat di luar kelas.Setelah melakukan salam atau panganjali serta melantunkan mantra guru puja siswa duduk kembali dan melanjutkan ke proses belajar mengajar. Dalam proses belajar mengajar siswa di SDN 1 Sumerta diajarkan untuk duduk dengan posisi yang nyaman, dengan posisi punggung, leher dan kepala tegak lurus. Kedua tangan bisa diletakkan diatas meja dan pandangan lurus ke depan. Dengan posisi tersebut siswa akan lebih fokus dan juga berkonsentrasi ketika menerima pelajaran yang diberikan oleh guru.

\section{d. Meningkatkan Sradhha dan Bhakti}

Setiap mengawali kegiatan pembelajaran dan pertemuan ektraYoga di SDN 1 Sumerta selalu memulai dengan doa. Seperti yang termuat dalam kurikulum 2013 terutama dalam kompetensi inti satu dinyatakan bahwa menerima dan menjalankan ajaran agama yang dianutnya (religius). Untuk penerapan Kurikulum 2013 ini sebelum proses belajar mengajar siswa diajak mengucapkan panganjali umat serta mengucapkan dainika upasana (doa sehari-hari) yaitu guru puja.

Pengucapan panganjali umat "Om Swastyastu" yang artinya semoga selamat atas wara nugraha Ida Sang Hyang Widhi 
Wasa dalam buku Swastikarana (Tim Penyusun, 2013: 236). Serta melantunkan mantra guru puja "Om Gurur Brahma, Gurur visnu, gurur deva mahesvara, gurur saksat parambrahma tasmai sri guruve namah" dalam buku Swastikarana (Tim Penyusun, 2013: 326) yang artinya $\mathrm{Om}$ Hyang Widhi, hamba memujamu dalam wujudmu Brahma, Wisnu dan Siwa. Guru agung jagatraya, alam semesta. Semoga hamba mencapai kesempurnaan dan kesejahteraan.

"Om Swastyastu” apabila dimaknai dengan sungguh-sungguh akan membawa keharmonisan dengan diri sendiri sebagai makhluk individu dan harmonis dengan sesama sebagai makhluk sosial, ini merupakan penerapan dari ajaran Yogapada bagian yama. Pengucapan $\mathrm{Om}$ dengan sikap bathin berdoa akan menguatkan eksistensi Atman sebagai sang jiwa menguasai kesadaran budhi dan kecerdasan intelektual serta mengendalikan kepekaan emosional. Dalam mengucapkan Om Swastyastu yang utama adalah ekspresi jiwa dimulai dari gerakan tubuh, bahasa hati yang suci dan tersenyum dalam buku Swastikarana (Tim Penyusun, 2013: 239) hal tersebut juga merupakan cerminan dari ajaran Yoga.Begitu pula dengan mantra guru puja jika dilantunkan dengan tulus ikhlas, maka sang guru alam semesta akan senantiasa menemani dalam setiap langkah yang dilakukan oleh siswa.

Doa adalah perwujudan cinta manusia kepada Tuhan. Kecintaan manusia kepada Tuhan tidak dapat dipisahkan dari kehidupan manusia. Hal ini, dikarenakan pemujaan kepada Tuhan adalah inti, nilai, dan makna kehidupan yang sebanarnya. Penyebab hal itu terjadi karena Tuhan pencipta alam semesta (Prasetya, 2004:60).

Kegiatan berdoa sebelum melaksanakan Yoga secara otomatis mengajak siswa untuk meningkatkan sradha dan bhakti kepada Ida
Sang Hyang Widhi dengan memusatkan pikiran dan kesungguhan hati, karena setiap apapun yang kita lakukan haruslah memohon restu kepada Beliau agar selalu diberikan pikiran yang terang.

\section{SIMPULAN}

Dampak Implementasi Pembelajaran Yogadi SDN 1 Sumerta ialah menyehatkan fisik akan nampak bila tekun dalam melaksanakan latihan yoga ialah meningkatkan fleksibilitas, kekuatan, mengembangkan otot, dan mencegah nyeri; menyeimbangkan emosi, Yoga memiliki banyak manfaat bagi ketenangan pikiran, kesehatan, kesimbangan dalam pengontrolan emosi, mengatasi masalah dengan keadaan emosi yang positif, dan berbagaimacam solusi dapat ditemukan untuk mengatasi permasalahan kehidupan dengan cara tekun melaksanakan Yoga; meningkatkan konsentrasi melakukan asana; meningkatkan sradha dan bhakti melaui doa setiap kegiatan pembelajaran dan pertemuan ektra Yoga di SDN 1 Sumerta dengan memusatkan pikiran dan kesungguhan hati

\section{DAFTAR PUSTAKA}

Maswinara, I Wayan, 1999. Sistem Filsafat Hindu. Surabaya: Paramita.

Acarya, Avadhutika Anandamitra. 2013. Yoga Untuk Kesehatan. Jakarta Barat: Persatuan Ananda Marga Indonesia

Depdiknas. 1994. Kamus Besar Bahasa Indonesia Edisi Kedua. Departemen Pendidikan nacional. Jakarta: Balai Pustaka.

Donder, I Ketut. 2004. Sisya Sista. Denpasar: Pustaka Bali Post.

Kamajaya, Gede. 1993. Yoga Kundalini Cara Untuk Mencapai Siddhi dan Moksa. Surabaya: Paramita.

Madja, I Ketut. 2008. “Konsep Yoga Patanjali dan Yoga Wrhaspati Tattwa (sebuah studi 
komparatif)". Tesis(tidak diterbitkan). Denpasar: Institut Hindu Dharma Negeri Denpasar.

Nurdin, Syafruddin dan Usman, Basyiruddin. 2002. Guru Profesional dan Implementasi Kurikulum. Jakarta: Ciputat Pers.

Prasetya, Joko Tri. 2004. Ilmu Budaya Dasar. Jakarta: Rineka Cipta.

Radhakrisnan (1987:9)

Sarasvati, Svami Satyananda. 2002. Asanas,

Pranayama, Mudra, dan Bandha. Surabaya: Paramita.

Saraswatî, Svâmî Satya Prakâs. 2005.Pâtañjali Râja Yoga(J.B.A.F. Mayor Polak Penerjemah).Surabaya: Parâmita
Somvir. 2008. Mari BerYoga (Yoga untuk Badan, Pikiran dan Jiwa). Denpasar: Bali-India Pondation.

Suhardana, K.M. 2006. Etika dan Moralitas Hindu Bahan Kajian Untuk Memperbaiki Tingkah Laku. Surabaya: Paramita.

Tim Penyusun, 2013. Swastikarana. Surabaya: Paramita.

Tim-Penyusun, 2006. Siwa Tattwa. Denpasar: Pemerintah Propinsi Bali.

Vivekananda, Svami. 2008. Filosofis dan Keagamaan. Surabaya: Paramita.

Zain, Badudu. 2001. Kamus Lengkap Bahasa Indonesia. Jakarta: Pustaka Sinar Harapan. 